\title{
Analysis of Microbial Diversity in Soil under Ginger Cultivation
}

\author{
Yiqing Liu, ${ }^{1}$ Lin Wu, ${ }^{1}$ Xingwen Wu, ${ }^{2}$ Honghai Li, ${ }^{3}$ Qinhong Liao, \\ Xiaojing Zhang, ${ }^{4}$ Zhiqiang Sun, ${ }^{4}$ and Wenhua $\mathrm{Li}^{4}$ \\ ${ }^{1}$ Chongqing Key Laboratory of Economic Plant Biotechnology, Collaborative Innovation Center of \\ Special Plant Industry in Chongqing, Institute of Special Plants, College of Forestry \& Life Science, \\ Chongqing University of Arts and Sciences, Yongchuan, Chongqing 402160, China \\ ${ }^{2}$ Liangping Agro-Technical Extension Station, Liangping, Chongqing 405200, China \\ ${ }^{3}$ Chongqing Engineering and Technology Research Center for Utilization of Ginger Resource, \\ Chongqing Tianpei Agro-Tech Co. Ltd., Yongchuan, Chongqing 402189, China \\ ${ }^{4}$ Yantai Lvyun Biotechnology Co. Ltd., Yantai 264003, China
}

Correspondence should be addressed to Honghai Li; 1207118074@qq.com

Received 22 May 2017; Accepted 11 September 2017; Published 23 October 2017

Academic Editor: Maurizio Sanguinetti

Copyright (C) 2017 Yiqing Liu et al. This is an open access article distributed under the Creative Commons Attribution License, which permits unrestricted use, distribution, and reproduction in any medium, provided the original work is properly cited.

\begin{abstract}
Ginger is a perennial monocotyledonous herb, which can be used as both a vegetable and a medicinal plant. However, it is susceptible to various plant pathogens. Microbial diversity in soil is related closely to the health and productivity of plant crops including ginger. In the current study, we compared microbial diversity from soil samples under ginger cultivation (disease incidence of $>50 \%$ [relatively unhealthy sample] versus disease incidence of $<10 \%$ [relatively healthy sample]). The bacterial and fungal taxa were analyzed by Illumina-based sequencing, with 16S and ITS identification, respectively. Both bacterial and fungal OTUs were significantly more in the healthy soil sample than the unhealthy sample. Moreover, the dominant bacterial and fungal genera were detected to be different in each sample. Rhodanobacter and Kaistobacter were the dominant bacterial genera in the healthy sample, while Rhodoplanes and Bradyrhizobium were the dominant genera in the unhealthy sample. For fungal analysis, Cladosporium, Cryptococcus, and Tetracladium were the dominant genera in the healthy sample, while Lecanicillium, Pochonia, and Rhodotorula were the dominant genera in the unhealthy sample. Collectively, the basic information of microbial diversity in ginger soil is helpful for elucidating the ginger-microbe interactions and potentially selecting suitable plant growth-promoting rhizobacteria and biocontrol agents for ginger production.
\end{abstract}

\section{Introduction}

Ginger (Zingiber officinale) is a perennial monocotyledonous herb, which can be used as both a vegetable and a medicinal plant. It is widely employed in Chinese, Ayurvedic medicines and home remedies since antiquity for many ailments including pain, inflammation, and gastrointestinal disorders [1]. However, ginger is subject to various diseases during growth stages [2-5]. The occurrence of these diseases results in significant yield reductions in ginger. For instance, Enterobacter cloacae causes ginger rhizome rot [6], while Erwinia chrysanthemi is the causal agent of ginger soft rot [7]. Root-rot disease, caused by the fungal pathogen, Pythium myriotylum, was reported to decimate ginger in field plantings, when temperatures ranged from 26 to $30^{\circ} \mathrm{C}$ and the soil was saturated with water due to continuous rainfall [8]. Ginger rhizomes infected with Fusarium oxysporum exhibit yellow shoots and die after a few weeks [9], and it is also a devastating postharvest disease for stored ginger [10].

Soil microbial community plays an important role in nutrient mobilisation and uptake for plant. They promote plant growth and suppress disease by their various activities, like phosphate and sulphate solubilisation, plant growth promotion, siderophore production, nitrogen fixation, denitrification, immune modulation, signal transduction, and pathogen control [11]. The objectives of the present study were 
to analyze and compare the microbial diversity from the soil under the cultivation of ginger with low disease incidence (healthy sample) and high disease incidence (unhealthy sample). Specially, total microbial DNA of ginger soil samples was purified and analyzed by Illumina-based sequencing. The bacterial and fungal communities were further compared and the vertically transmitted bacterial and fungal taxa were elucidated in the study.

\section{Material and Methods}

2.1. Soil Sampling and DNA Extraction. The soil samples were collected from the organic ginger field in Yongchuan, Chongqing, China (N29 $10^{\prime} 57.80^{\prime \prime}$, E105 $\left.50^{\prime} 1.77^{\prime \prime}\right)$, in Sep, 2016. This organic farm with total of $50,000 \mathrm{~m}^{2}$ area is divided into 100 planting units with each of $500 \mathrm{~m}^{2}$ area. When the gingers were harvested in Sep, 2016, it was found that the disease incidence varied among each planting unit. In order to analyze the microbial diversity, the rhizospheric soil samples were collected from two groups (healthy group versus disease group). Soil samples were collected at a depth of approximately $15 \mathrm{~cm}$, in sterile polythene bags, and stored in refrigerator until DNA extraction. In Group I, the soil samples were taken from nine ginger-planting units in which the disease incidence was lower than $10 \%$; in Group II, the soil samples were taken from nine ginger-planting units in which the disease incidence was more than $50 \%$.

The soil samples from the two groups above were used for total DNA extraction. The total DNA was extracted using EZNA $^{\circledR}$ Soil DNA Kit (Omega Bio-Tek, USA) according to the manufacture's instruction. Briefly, about $1 \mathrm{~g}$ soil sample was added to $15 \mathrm{~mL}$ centrifuge tube with glass beads. Total DNA was obtained after the procedures of lysis, centrifugation, binding on DNA binding column, elution, and purification. Total DNA concentration and purity were monitored on $1 \%$ agarose gels.

2.2. Amplicon Generation and Illumina MiSeq Sequencing. The pair of primers 515F (5'-GTGCCAGCMGCCGCGGTAA- $\left.3^{\prime}\right)$ and 907R (5'-CCGTCAATTCCTTTGAGTTT- $3^{\prime}$ ) were used to amplify the V4-V5 regions, a hypervariable area of the $16 \mathrm{~S}$ rRNA gene. The primers ITS5-1737F ( $5^{\prime}$-GGAAGTAAAAGTCGTAACAAGG-3' $)$ and ITS2-2043R ( $5^{\prime}$-GCTGCGTTCTTCATCGATGC- $\left.3^{\prime}\right)$ targeting the ITS1 regions of fungal rRNA genes were adopted to analyze fungal taxa [12]. Both forward and reverse primers were tagged with adapter, pad, and linker sequencing. Each barcode sequence was added to the reverse primer for pooling multiple samples into one run of sequencing. All PCR amplifications were performed in terms of previously reported method [13]. The reaction conditions were as follows: an initial denaturation at $98^{\circ} \mathrm{C}$ for $1 \mathrm{~min}$, each of 30 cycles at $98^{\circ} \mathrm{C}$ for $10 \mathrm{~s}, 55^{\circ} \mathrm{C}$ for $30 \mathrm{~s}$, and $72^{\circ} \mathrm{C}$ for $60 \mathrm{~s}$, with a final extension at $72^{\circ} \mathrm{C}$ for $5 \mathrm{~min}$. After mixing the PCR products of the triplicate, detection was implemented by $2 \%(\mathrm{w} / \mathrm{v})$ agarose gel electrophoresis, and then the PCR products were purified by the AxyPrep Gel Extraction Kit (Axygen, USA). Amplicons from each reaction mixture were quantified fluorometrically, normalized, and pooled at equimolar ratios based on the
TABLE 1: Number of OTUs in the samples.

\begin{tabular}{lc}
\hline Microbial samples & OTUs \\
\hline Bacteria & \\
Sample 1 & 1347 \\
Sample 2 & 1179 \\
Sample 3 & 1506 \\
Sample 4 & 1661 \\
Fungi & \\
Sample 1 & 183 \\
Sample 2 & 196 \\
Sample 3 & 202 \\
Sample 4 & 221 \\
\hline
\end{tabular}

Note. Samples 1 and 2 represent the two replicates of soil samples under ginger cultivation with disease incidence of $>50 \%$ (relatively unhealthy sample), while Samples 3 and 4 represent the two replicates of soil samples under ginger cultivation with disease incidence of $<10 \%$ (relatively healthy sample).

concentration of each amplicon. The sequencing libraries were generated using NEB Next Ultra ${ }^{\mathrm{TM}}$ DNA Library Prep Kit for Illumina (New England Biolabs) following manufacturer's recommendations, and index codes were added. The library quality was assessed on the Qubit ${ }^{@} 2.0$ Fluorometer (Thermo Scientific) and Agilent Bioanalyzer 2100 system (Agilent Technologies). Finally, the libraries were sequenced on an Illumina MiSeq platform $[14,15]$.

2.3. Data Preprocessing. All sequence reads with the same tag were assigned to the same sample according to the unique barcodes (raw tags). The raw tags were further filtered by clean tags, and the quality of clean tags was detected by Qiime (http://qiime.org/index.html) [16, 17]. Rarefaction analysis was implemented based on MOTHUR package, using operational taxonomic units (OTUs) grouped at $97 \%$ sequences similarity [18]. The numbers of randomly selected sequences and corresponding OTUs under the sobs diversity index were employed as the variables.

\section{Results and Discussion}

The soil provides a great variety of microhabitats for myriad organisms of different size, physiological activity, behavior, and ecosystem function [19]. The extent of the diversity of microorganisms in soil is critical to the maintenance of health and quality of soil and plant, as a wide range of microorganisms is involved in important soil functions [20]. Recently, there have been a few studies on reports of ginger diseases $[14,15,21,22]$. However, to the best of our knowledge, the reports on soil microbes in ginger fields are limited. In the present study, we compared the microbial diversity from soil samples of ginger-planting field (ginger with low disease incidence [healthy sample] versus ginger with high disease incidence [unhealthy sample]). The data of this present study showed that both bacterial and fungal OTUs were significantly more in the healthy soil sample than the unhealthy sample (Table 1). These findings were consistent with the previous study about microbial diversity in the soil under cultivation of potato [23] and maize [24]. 


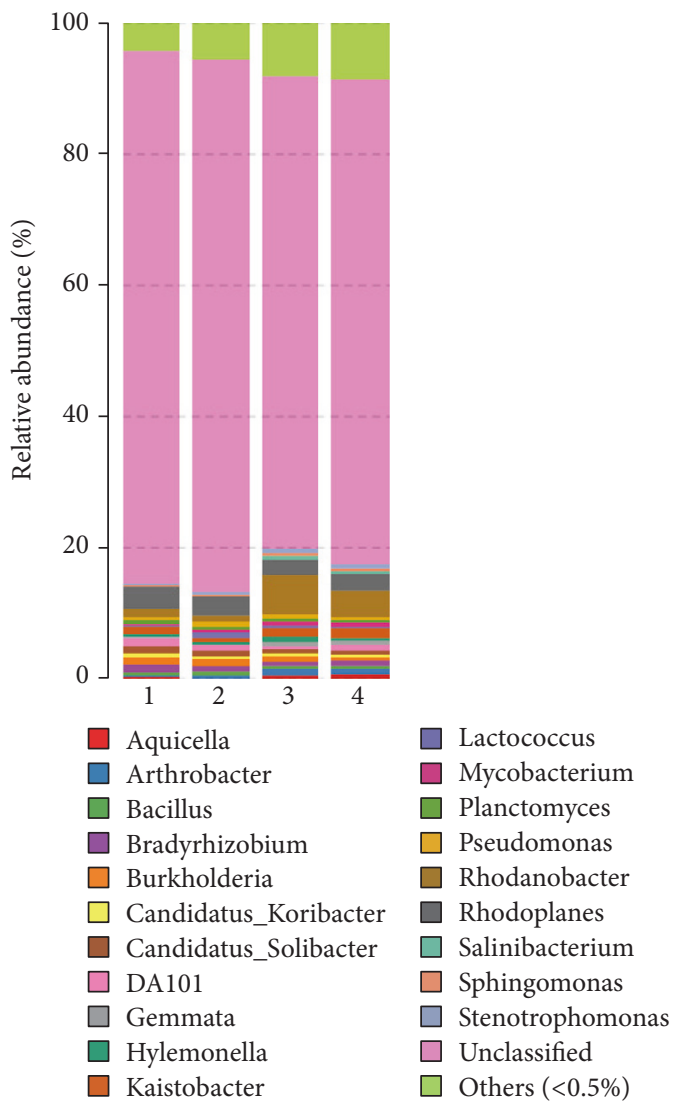

FIgURE 1: Relative abundance of bacterial genera. Samples 1 and 2 represent the two replicates of relatively unhealthy soil samples, while Samples 3 and 4 represent the two replicates of relatively healthy soil samples.

More specially, the dominant bacterial and fungal genera were detected to be different in each sample. Rhodanobacter and Kaistobacter were the dominant bacterial genera in the healthy sample, while Rhodoplanes and Bradyrhizobium were the dominant genera in the unhealthy sample (Figure 1). Rhodanobacter spathiphylli sp. Nov. was isolated from a gamma proteobacterium isolated from the roots of Spathiphyllum plants and showed biocontrol activity towards the root-rot plant pathogen Cylindrocladium spathiphylli [25]. For fungal analysis, Cryptococcus, Cladosporium, and Tetracladium were the dominant genera in the healthy sample, while Lecanicillium, Pochonia, and Rhodotorula were the dominant genera in the unhealthy sample (Figure 2). Cryptococcus genus has been reported to be with potential plant growth-promoting traits [26], and Lecanicillium fungicola is a causal agent of dry bubble disease for many crops [27].

\section{Conclusions}

The current knowledge concerning the microbial diversity, particularly bacteria and fungi in ginger field, has the potential to understand the complex ecosystem of microbemicrobe and microbe-ginger interaction. The dominant

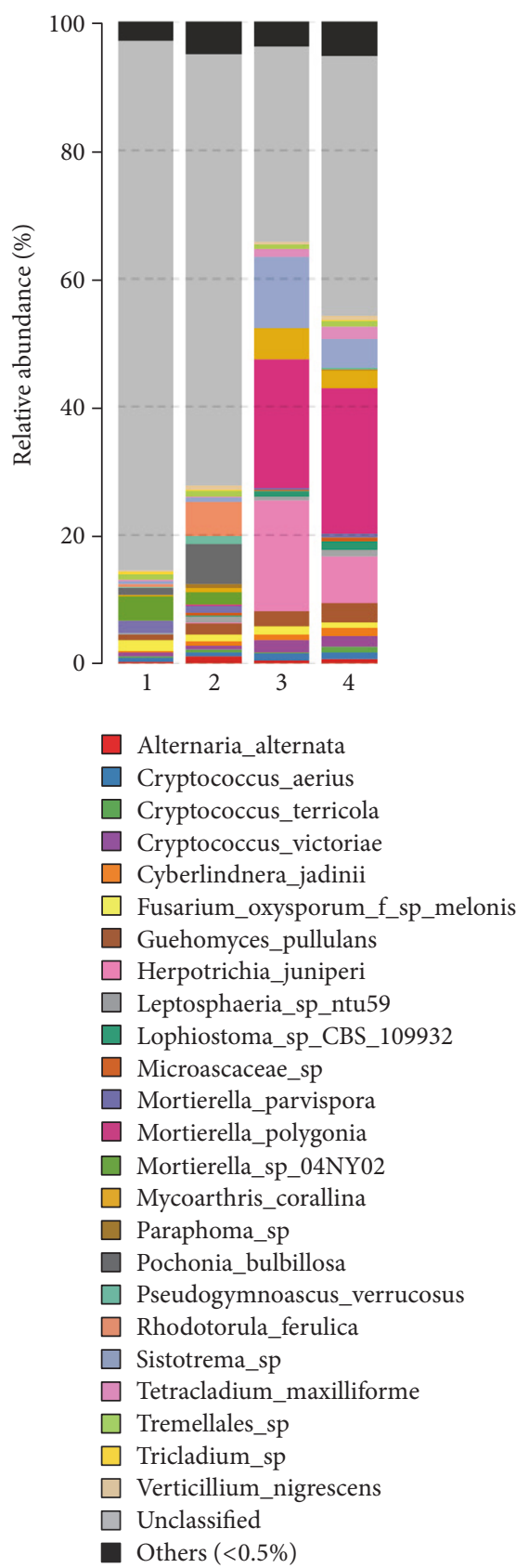

FIgURE 2: Relative abundance of fungal genera. Samples 1 and 2 represent the two replicates of relatively unhealthy soil samples, while Samples 3 and 4 represent the two replicates of relatively healthy soil samples.

bacterial and fungal genera in the ginger soil samples (healthy sample versus unhealthy sample) identified have the potential to explore biocontrol agents and pathogens. This study provides implications for maintenance of soil health and sustainable agriculture of ginger production.

\section{Conflicts of Interest}

The authors declare that they have no conflicts of interest. 


\section{Acknowledgments}

This work was supported by the Scientific Research Fund of Chongqing Education Commission (KJZH14216) and Chongqing Key Discipline Construction of Forestry.

\section{References}

[1] K. Srinivasan, "Ginger rhizomes (Zingiber officinale): a spice with multiple health beneficial potentials," PharmaNutrition, vol. 5, no. 1, pp. 18-28, 2017.

[2] Q. Peng, Y. Yuan, and M. Gao, "Bacillus pumilus, a novel ginger rhizome rot pathogen in China," Plant Disease, vol. 97, no. 10, pp. 1308-1315, 2013.

[3] V. Shanmugam, H. Thakur, J. Kaur, S. Gupta, S. Rajkumar, and N. P. Dohroo, "Genetic diversity of Fusarium spp. inciting rhizome rot of ginger and its management by PGPR consortium in the western Himalayas," Biological Control, vol. 66, no. 1, pp. $1-7,2013$.

[4] D. P. Le, M. Smith, G. W. Hudler, and E. Aitken, "Pythium soft rot of ginger: Detection and identification of the causal pathogens, and their control," Crop Protection, vol. 65, pp. 153167, 2014.

[5] D. Prasath, R. Karthika, N. T. Habeeba et al., "Comparison of the transcriptomes of ginger (Zingiber officinale Rosc.) and mango ginger (Curcuma amada Roxb.) in response to the bacterial wilt infection," PLoS ONE, vol. 9, no. 6, Article ID e99731, 2014.

[6] S. D. Jolad, R. C. Lantz, J. C. Guan, R. B. Bates, and B. N. Timmermann, "Commercially processed dry ginger (Zingiber officinale): composition and effects on LPS-stimulated $\mathrm{PGE}_{2}$ production," Phytochemistry, vol. 66, no. 13, pp. 1614-1635, 2005.

[7] A. M. Stirling, "Erwinia chrysanthemi, the cause of soft rot in ginger (Zingiber officinale) in Australia," Australasian Plant Pathology, vol. 31, no. 4, pp. 419-420, 2002.

[8] G. R. Stirling, U. Turaganivalu, A. M. Stirling, M. F. Lomavatu, and M. K. Smith, "Rhizome rot of ginger (Zingiber officinale) caused by Pythium myriotylum in Fiji and Australia," Australasian Plant Pathology, vol. 38, no. 5, pp. 453-460, 2009.

[9] K. A. Nishijima, A. M. Alvarez, P. R. Hepperly et al., "Association of Enterobacter cloacae with rhizome rot of edible ginger in Hawaii," Plant Disease, vol. 88, no. 12, pp. 1318-1327, 2004.

[10] Y. Liu, M. Wisniewski, J. F. Kennedy, Y. Jiang, J. Tang, and J. Liu, "Chitosan and oligochitosan enhance ginger (Zingiber officinale Roscoe) resistance to rhizome rot caused by Fusarium oxysporum in storage," Carbohydrate Polymers, vol. 151, pp. 474479, 2016.

[11] O. Prakash, R. Sharma, P. Rahi, and N. Karthikeyan, "Role of Microorganisms in Plant Nutrition and Health," Nutrient Use Efficiency: From Basics to Advance, pp. 125-161, 2015.

[12] P. H. Degnan and H. Ochman, "Illumina-based analysis of microbial community diversity," The ISME Journal, vol. 6, no. 1, pp. 183-194, 2012.

[13] S. Jiao, Z. Liu, Y. Lin, J. Yang, W. Chen, and G. Wei, "Bacterial communities in oil contaminated soils: Biogeography and cooccurrence patterns," Soil Biology \& Biochemistry, vol. 98, pp. 64-73, 2016.

[14] B. Huang, J. Li, W. Fang et al., "Effect of Soil Fumigation on Degradation of Pendimethalin and Oxyfluorfen in Laboratory and Ginger Field Studies," Journal of Agricultural and Food Chemistry, vol. 64, no. 46, pp. 8710-8721, 2016.
[15] Y. Huang, Z. Kuang, W. Wang, and L. Cao, "Exploring potential bacterial and fungal biocontrol agents transmitted from seeds to sprouts of wheat," Biological Control, vol. 98, pp. 27-33, 2016.

[16] J. G. Caporaso, C. L. Lauber, W. A. Walters et al., "Ultrahigh-throughput microbial community analysis on the Illumina HiSeq and MiSeq platforms," The ISME Journal, vol. 6, no. 8, pp. 1621-1624, 2012.

[17] N. A. Bokulich, S. Subramanian, J. J. Faith et al., "Qualityfiltering vastly improves diversity estimates from Illumina amplicon sequencing," Nature Methods, vol. 10, no. 1, pp. 57-59, 2013.

[18] R. C. Edgar, "UPARSE: highly accurate OTU sequences from microbial amplicon reads," Nature Methods, vol. 10, no. 10, pp. 996-998, 2013.

[19] H. Ferris and H. Tuomisto, "Unearthing the role of biological diversity in soil health," Soil Biology \& Biochemistry, vol. 85, pp. 101-109, 2015.

[20] P. Garbeva, J. A. Van Veen, and J. D. Van Elsas, "Microbial diversity in soil: selection of microbial populations by plant and soil type and implications for disease suppressiveness," Annual Review of Phytopathology, vol. 42, pp. 243-270, 2004.

[21] G. E. Thomas, K. A. Geetha, L. Augustine, S. Mamiyil, and G. Thomas, "Analyses between reproductive behavior, genetic diversity and Pythium responsiveness in Zingiber spp. reveal an adaptive significance for hemiclonality," Frontiers in Plant Science, vol. 7, no. 2016, article no. 1913, 2016.

[22] X. Liu, D. Yan, C. Ouyang et al., "Oils extracted from Eupatorium adenophorum leaves show potential to control Phythium myriotylum in commercially-grown ginger," PLoS ONE, vol. 12, no. 5, p. e0176126, 2017.

[23] R. P. Larkin, "Relative effects of biological amendments and crop rotations on soil microbial communities and soilborne diseases of potato," Soil Biology \& Biochemistry, vol. 40, no. 6, pp. 1341-1351, 2008.

[24] P. Garbeva, J. Postma, J. A. Van Veen, and J. D. Van Elsas, “Effect of above-ground plant species on soil microbial community structure and its impact on suppression of Rhizoctonia solani AG3," Environmental Microbiology, vol. 8, no. 2, pp. 233-246, 2006.

[25] D. De Clercq, S. Van Trappen, I. Cleenwerck et al., "Rhodanobacter spathiphylli sp. nov., a gammaproteobacterium isolated from the roots of Spathiphyllum plants grown in a compost-amended potting mix," International Journal of Systematic and Evolutionary Microbiology, vol. 56, no. 8, pp. 1755-1759, 2006.

[26] P. Nutaratat, N. Srisuk, P. Arunrattiyakorn, and S. Limtong, "Plant growth-promoting traits of epiphytic and endophytic yeasts isolated from rice and sugar cane leaves in Thailand," Fungal Biology, vol. 118, no. 8, pp. 683-694, 2014.

[27] R. L. Berendsen, J. J. P. Baars, S. I. C. Kalkhove, L. G. Lugones, H. A. B. WöSten, and P. A. H. M. Bakker, "Lecanicillium fungicola: Causal agent of dry bubble disease in white-button mushroom," Molecular Plant Pathology, vol. 11, no. 5, pp. 585-595, 2010. 


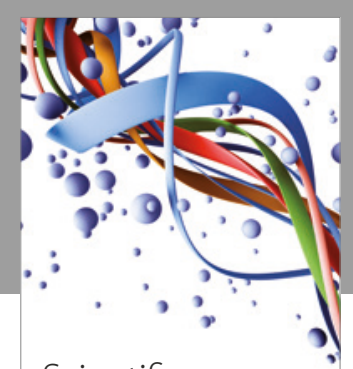

Scientifica
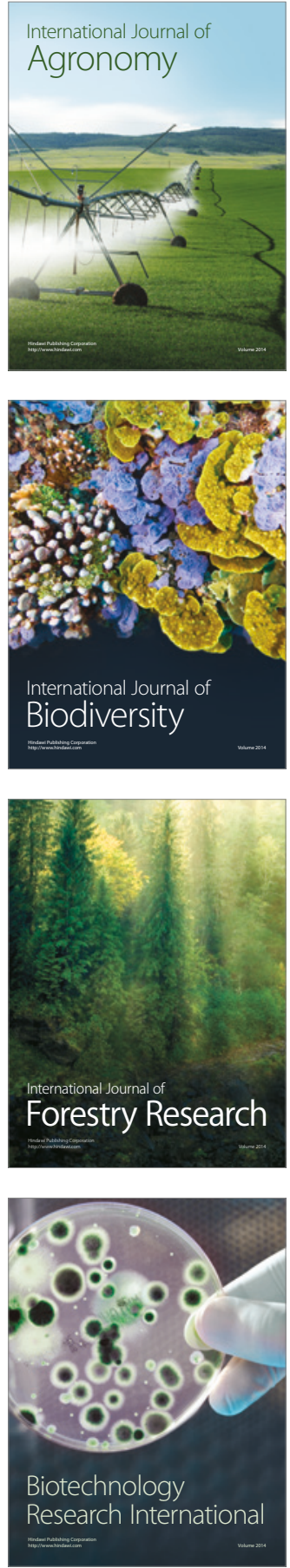
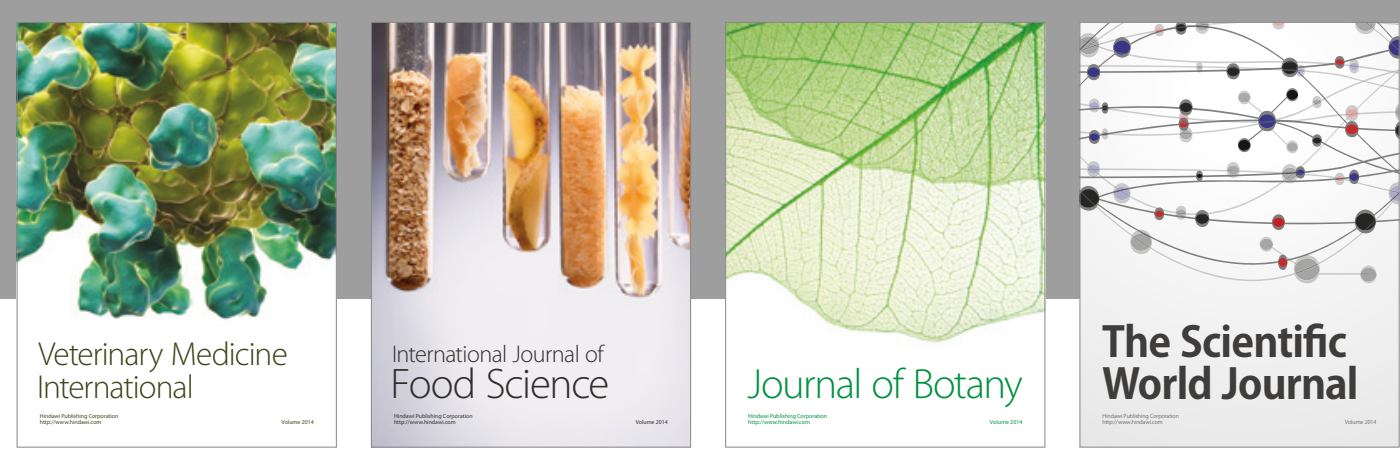

The Scientific

\section{World Journal}

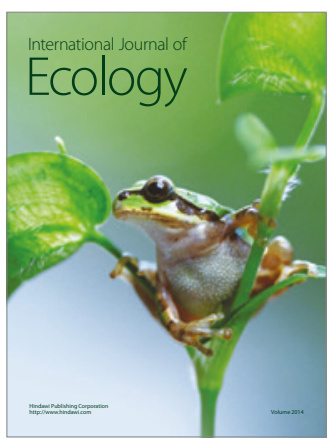

\section{Hindawi}

Submit your manuscripts at

https://www.hindawi.com
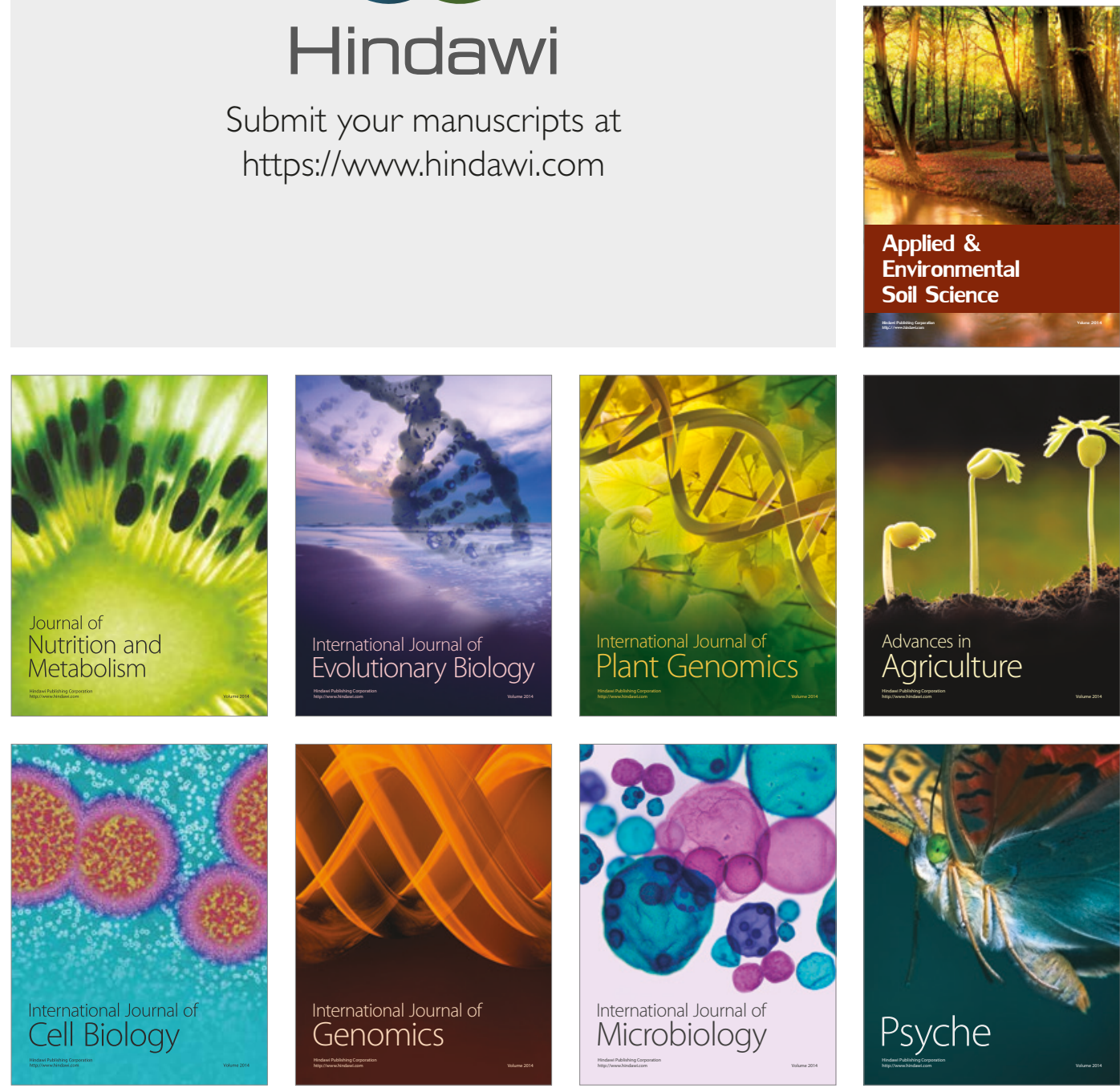

hternational Journal of Microbiology
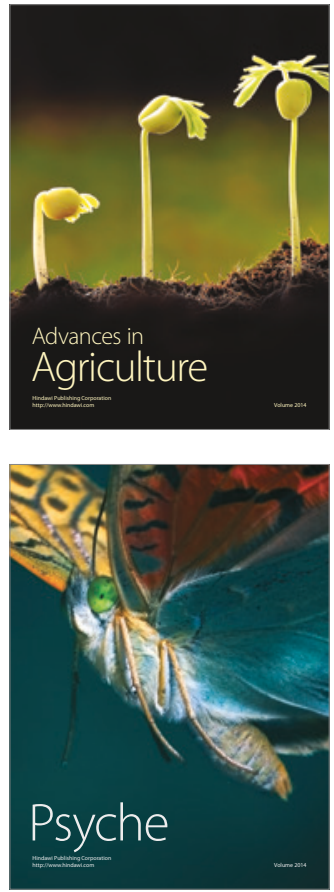